\title{
Adoption and Maintenance of Four Health Behaviors: Theory-Guided Longitudinal Studies on Dental Flossing, Seat Belt Use, Dietary Behavior, and Physical Activity
}

\author{
Ralf Schwarzer, Ph.D., Benjamin Schüz, M.Sc., Jochen P. Ziegelmann, Ph.D., and Sonia Lippke, Ph.D. \\ Freie Universität Berlin \\ Aleksandra Luszczynska, Ph.D. \\ University of Sussex and Warsaw School of Social Psychology
}

Urte Scholz, Ph.D.

Universität Zürich

\begin{abstract}
Background: Adoption and maintenance of health behaviors are of ten poorly predicted by behavioral intentions. To bridge the gap between intentions and behavior, strategic planning and recovery self-efficacy have been suggested as proximal predictors. Purpose: The aim was to examine the usefulness of a prediction model that includes planning and self-efficacy as postintentional mediator variables. Methods: Four longitudinal studies were conducted on dental flossing (Study I, $N=157$ ), seat belt use (Study II, $N=298$ ), dietary behaviors (Study III, $N=700$ ), and physical activity (Study IV, $N=365$ ). Dental flossing and seat belt use were assessed in students by paper-and-pencil questionnaires, whereas dietary behavior and physical activity inventories were presented to the general public in the internet. Results: By structural equation modeling, it was found that one common model fits all four data sets well. Results differed in terms of variance accounted for, but the overall patterns of estimated parameters were similar across samples. Conclusions: Self-efficacy and planning seemed to be functional as proximal predictors of health behaviors, whereas health risk perception appeared to be a negligible factor. When predicting health behaviors, self-regulatory variables should be used in addition to the behavioral intention.
\end{abstract}

\section{INTRODUCTION}

The predictor of health behavior most frequently used is the behavioral intention (e.g., "I intend to run five times a week for at least 30 minutes"), as, for example, in Protection Motivation Theory (1) or in the Theory of Planned Behavior (2). But people do not always behave

We gratefully acknowledge the support of Falko Sniehotta and Amelie Wiedemann (dental flossing study), Axinja Kalusche (nutrition study), and Jens M. D. Rademacher (online studies).

Reprint Address: R. Schwarzer, Ph.D., Health Psychology, Freie Universität Berlin, Habelschwerdter Allee 45, 14195 Berlin, Germany. E-mail: health@zedat.fu-berlin.de in accordance with their intentions. Empirical evidence (e.g., 3) suggests that about one fifth to one fourth of the behavior variance is accounted for by intentions in crosssectional data, but much less in longitudinal data. This disagreement between intention and behavior is due to several reasons. For example, unforeseen barriers could emerge, or people might give in to temptations. Therefore, intention needs to be supplemented by other, more proximal factors that might compromise or facilitate the translation of intentions into action. Some of these postintentional factors have been identified, such as perceived self-efficacy $(4,5)$ and strategic planning $(6,7)$.

In this article, four studies aimed at four preventive health behaviors (dental flossing, seat belt use, preventive nutrition, and physical exercise) examine the role of these two factors, namely self-efficacy and planning in initiation and adherence to health behaviors. The studies are based on different samples in two countries.

\section{A Social-Cognitive Prediction Model for Health Behavior Change}

The Health Action Process Approach (HAPA) (6-8) extends the previously-mentioned models into a process that includes postintentional factors. It suggests a distinction between (a) preintentional motivation processes that lead to a behavioral intention, and (b) postintentional volition processes that lead to the actual health behavior. Within both phases, different patterns of social-cognitive predictors may emerge. In the initial motivation phase, a person develops an intention to act. In this phase, risk perception is seen as a distal antecedent within the motivation phase. Risk perception in itself is insufficient to enable a person to form an intention. Rather, it sets the stage for a contemplation process and further elaboration of thoughts about consequences and competencies. Similarly, outcome expectancies ("If I exercise five times per week, I will reduce my cardiovascular risk") are chiefly seen as being important in the motivation phase, when a person balances the pros and cons of certain behavior consequences. Further, one needs to believe in one's capability to perform a desired action ("I am capable of adhering to my self-imposed exercise schedule in spite of the temptation to watch TV"). After a person develops an 
inclination toward a particular health behavior, the "good intention" has to be transformed into detailed instructions on how to perform the desired action (strategic planning; see 4,8 ). Once an action has been initiated, it has to be maintained. This is not achieved through a single act of will, but it involves self-regulatory skills and strategies. Thus, intentions may be seen as a suitable predictor of behavior, unless the postintentional phase is further broken down into more proximal factors, such as planning and perceived self-efficacy, and so forth. In the following, these two constructs will be described in more detail.

\section{Phase-Specific Self-Efficacy Beliefs}

The concept of phase-specific self-efficacy has been brought up by Marlatt, Baer, and Quigley (9) in the domain of addictive behaviors, and it has been successfully applied to other health behaviors $(4,5,10)$. The rationale for the distinction between several phase-specific self-efficacy beliefs is that during the course of health behavior change, different tasks have to be mastered, and thus different selfefficacy beliefs are required to master these tasks successfully. For example, a person might be confident in his or her capability to be physically active in general (i.e., high motivational self-efficacy), but might not be very confident to resume physical activity after a setback (low recovery self-efficacy). Motivational self-efficacy refers to the first phase of the process, in which an individual does not yet act, but develops a motivation to do so. Recovery self-efficacy, on the other hand, addresses the experience of failure and recovery from setbacks. It is most functional when it comes to resume an interrupted chain of action. If a lapse occurs, individuals can fall prey to the "abstinence violation effect," that is, they attribute their lapse to internal, stable, and global causes, dramatize the event, and interpret it as a full-blown relapse (9). High self-efficacious individuals, however, avoid this effect by attributing the lapse to an external high-risk situation and by finding ways to control the damage and to restore hope. Recovery selfefficacy pertains to one's conviction of being able to get back on track after being derailed. The person trusts his or her competence to regain control after a setback or failure and to reduce harm. This distinction between phasespecific self-efficacy beliefs has proven useful in several domains of behavior change (cf. 9). Various authors $(11,12)$ have found evidence for phase-specific self-efficacy beliefs in the domain of exercise behavior (i.e., task selfefficacy, coping self-efficacy, and scheduling self-efficacy). In studies applying the HAPA model, phase-specific selfefficacy differed in the effects on various preventive health behaviors, such as breast self-examination (4), diet (13), and physical exercise $(5,10)$.

\section{Strategic Planning}

Good intentions are more likely to be translated into action when people develop success scenarios and preparatory strategies of approaching the difficult task. Mental simulation helps to identify cues for action. The terms planning or implementation intentions have been used to address this phenomenon. Lewin (14) has studied the importance of planning in the context of food choice, making a distinction between an overall plan and a specific plan to make the first step toward the goal. Leventhal, Singer, and Jones (15) have stated that fear appeals can facilitate health behavior change only when combined with specific instructions on when, where, and how to perform them. Renewed attention to planning emerged when the concept of implementation intentions was introduced (16). Mental simulation is more than simply an extension of the intention since the former includes situation parameters (when, where) and a preprogrammed sequence of action (how). It is more effective than intentions when it comes to the likelihood and speed of performance, mainly because the behavior is being elicited almost automatically when the relevant situational cues are encountered. People do not forget their intentions easily when specified in a when, where, and how manner (17; for an overview and meta-analysis, see 3). Several meta-analyses revealed moderate to high population effect sizes for the planningbehavior relationship $(d+=0.54 ; 55 ; d+=0.70 ; 3$; $d+=0.59$; 56). Therefore, the general emphasis of these four studies lies on the assumption that action plans constitute a valuable proximal construct by moving further into the volition phase, and by allowing a better prediction of behaviors.

\section{Aims of the Four Studies}

The general aim of all four studies is to examine the applicability of the HAPA model by replicating it across different health behaviors. The model used in the following studies includes three predictors of the behavioral intention (motivational self-efficacy, outcome expectancies, health risk perception) and three predictors of self-reported behavior (intention, recovery self-efficacy, planning). The following research questions have been posed: (a) Does a structural equation model, specified in terms of the HAPA, fit the data? (b) Do the two theoretical mediators, namely planning and recovery self-efficacy, account for the variance in self-reported health behaviors? So far, this set of variables has not been examined jointly for dental flossing, seat belt use, dietary behaviors, and physical activity.

\section{Data Analysis}

Path analysis with maximum likelihood estimation was employed (cf. 18) to examine associations between socialcognitive variables and behavior. In the hypothesized model, perceived risk, outcome expectancies, and motivational self-efficacy were specified as predictors of intention. Motivational self-efficacy was specified as a predictor of recovery self-efficacy. Intention and recovery self-efficacy were specified as predictors of planning. Finally, planning 
and recovery self-efficacy were specified as predictors of behavior.

Evaluation of the model-data fit was based on recommended indices: TLI, CFI, RMSEA, $\chi^{2} / d f$ and $\chi^{2}$. The following values indicate a good fit of the model to the data: TLI, CFI values ranged from .90 to 1, RMSEA values of .05 or less, $\chi^{2} / d f$ between 1 and 2 , and nonsignificant values of $\chi^{2}$ in a small sample (cf. 19). Missing data were treated with full information maximum likelihood imputation.

\section{STUDY I: DENTAL FLOSSING}

The first study examines dental flossing in a sample of 157 German students. The following analysis applies the HAPA model to a longitudinal data set with three points in time covering a 6-week period. The question is whether the model fits the data, and whether self-efficacy and planning constitute mediators.

\section{Method}

\section{Participants}

A total of 258 undergraduate students were invited to take part in the study. Informed consent was obtained from 252 participants. Of these, 95 dropped out at the second or third measurement point in time, 2 and 6 weeks after the initial assessment, respectively. Dropout analyses in terms of sex, age, and baseline behavior showed no significant differences (all $F \mathrm{~S}<1$ ) between the participants in the initial sample and those who completed all three waves of data collection, indicating that the longitudinal sample was representative for the entire sample. All further analyses were conducted with the longitudinal sample of 157 participants, ages 16 to $51 \quad(M=25.29, S D=7.03)$, $79.61 \%$ of them women. About $56 \%$ of respondents were single, all had completed high school, and $9 \%$ held a university degree.

\section{Procedure}

Participants were approached during lectures, were informed about the purpose and design of the study, and asked to participate on a voluntary basis. After giving informed consent, participants filled in baseline questionnaires and received postal follow-up questionnaires 2 weeks and 6 weeks later.

\section{Measures}

The Time 1 questionnaire assessed risk perception, motivational self-efficacy, outcome expectancies, and behavioral intentions. Measures of intention were based on previous research by Rise et al. (20), items for risk perception, motivational self-efficacy and outcome expectancies were adapted to dental flossing from previous research (21). At Time 2, planning and recovery self-efficacy were measured. All variables were assessed using 4-point scales ranging from 1 (totally disagree) to 4 (totally agree). Time 3 questionnaires assessed the behavioral outcome (flossing frequency) in a free response format, validated in previous research (21). Item examples as well as scale statistics can be found in Table 1. For correlations see Table 2.

\section{Results}

The hypothesized model fit the data well, with RMSEA $=.06(90 \% \mathrm{CI}=.05, .08), \chi^{2} / d f=1.59, \mathrm{CFI}=.96$, $\mathrm{TLI}=.94, \chi^{2}(124)=197, p<.001$. Figure 1 displays the parameter estimates (standardized solution). All manifest variables loaded significantly $(p<.05)$ on their hypothesized factors. Figure 1 displays the parameter estimates (standardized solution). Planning and self-efficacy emerged as mediators. Motivational self-efficacy accounted for $27 \%$ of variance of the recovery self-efficacy, attesting to the discriminant validity of the two constructs. Of the planning variance, $67 \%$ has been accounted for by intention and recovery self-efficacy, and $36 \%$ of the dental flossing variance has been explained jointly by planning and recovery self-efficacy. The indirect effect of intention on flossing was $.28(p<.05)$.

\section{STUDY II: SEAT BELT USE}

The second study examines seat belt use in a sample of 298 students in Poland. The following analysis applies the HAPA model to a longitudinal data set with three points in time covering a 7 -month period. The question is whether the model fit the data and whether self-efficacy and planning constitute mediators.

\section{Method}

\section{Procedure and Participants}

The research team visited six high schools during class hours and invited students to take part in a study after classes. Schools were randomly selected from the metropolitan area of Warsaw, Poland. The study was presented as an investigation of participants' beliefs concerning seat belt use and smoking. Students were informed that they would complete a second questionnaire 1 month later (Time 2) and a third one 6 months after the second (Time $3)$. Personal codes were used to ensure confidentiality.

Of 358 students participating in Wave 1, 298 participated in all data collections. They were 16 to 21 years old $(M=18.35, S D=1.06)$, and $55.5 \%$ were men. The majority of participants declared that they traveled by car every day $(30 \%)$, several times every week $(43.3 \%)$, or several times every month $(20.1 \%)$, with all participants traveling by car at least several times a year. Dropout analyses in terms of sex, age, and baseline behavior showed no significant differences between the initial sample and the final sample. 
TABLE 1

Overview of Variables and Psychometric Data of the Four Studies

\begin{tabular}{|c|c|c|c|c|c|c|c|}
\hline Construct & Sample & Item Example & $\begin{array}{l}\text { No. of } \\
\text { Items }\end{array}$ & $\begin{array}{l}\text { Response } \\
\text { Scale }\end{array}$ & $\alpha$ & $M$ & $S D$ \\
\hline \multirow[t]{4}{*}{ Risk perception } & 1 & $\begin{array}{l}\text { Not using dental floss would increase } \\
\text { my risk of contacting periodontal disease }\end{array}$ & 3 & $1-4$ & .73 & 2.88 & 0.74 \\
\hline & 2 & $\begin{array}{l}\text { Compared to other people of your age } \\
\text { and gender, how do you estimate the likelihood } \\
\text { that you will ever (a) sustain mild injuries } \\
\text { in a car accident, (b) be ticketed? }\end{array}$ & 3 & $-3-+3$ & .69 & -0.40 & 1.20 \\
\hline & 3 & $\begin{array}{l}\text { How severe is diabetes if it is not treated } \\
\text { medically or remains undetected? }\end{array}$ & 3 & $1-4$ & .80 & 7.47 & 3.12 \\
\hline & 4 & $\begin{array}{l}\text { If I continue my lifestyle, I have a high likelihood } \\
\text { of developing severe health problems. }\end{array}$ & 3 & $1-4$ & .80 & 2.45 & 0.86 \\
\hline \multirow[t]{4}{*}{ Outcome expectancies } & 1 & If I floss regularly, my teeth will feel cleaner. & 3 & $1-4$ & .71 & 2.97 & 0.73 \\
\hline & 2 & $\begin{array}{l}\text { If I would adopt regular seat belt use, } \\
\text { I would travel safer. }\end{array}$ & 3 & $1-6$ & .67 & 4.75 & 1.05 \\
\hline & 3 & $\begin{array}{l}\text { If I eat five portions of fruit and } \\
\text { vegetables every day, that would be } \\
\text { good for my health. }\end{array}$ & 3 & $1-4$ & .72 & 3.28 & 0.65 \\
\hline & 4 & $\begin{array}{l}\text { If I perform physical activity regularly, } \\
\text { that would be good for my health. }\end{array}$ & 3 & $1-4$ & .52 & 3.49 & 0.50 \\
\hline \multirow[t]{4}{*}{ Intention } & 1 & $\begin{array}{l}\text { I intend to floss regularly during } \\
\text { the next four weeks. }\end{array}$ & 3 & $1-4$ & .87 & 2.88 & 0.92 \\
\hline & 2 & $\begin{array}{l}\text { Within the next month, do you intend to } \\
\text { use the seat belt when you are } \\
\text { traveling on the rear seat? }\end{array}$ & 3 & $1-6$ & .75 & 3.67 & 1.44 \\
\hline & 3 & $\begin{array}{l}\text { I intend to eat at least five portions } \\
\text { of fruit and vegetables every day. }\end{array}$ & 3 & $1-4$ & .56 & 2.60 & 0.80 \\
\hline & 4 & $\begin{array}{l}\text { I intend to perform thirty minutes or more } \\
\text { of physical activities that make me sweat } \\
\text { at least three times per week. }\end{array}$ & 3 & $1-4$ & .79 & 3.29 & 0.74 \\
\hline \multirow[t]{4}{*}{ Motivational self-efficacy } & 1 & $\begin{array}{l}\text { I am confident that I can make sure to } \\
\text { floss daily, no matter what happens. }\end{array}$ & 3 & $1-4$ & .91 & 2.65 & 0.93 \\
\hline & 2 & $\begin{array}{l}\text { I am confident that I am able to initiate } \\
\text { regular seat belt use, even if I would have } \\
\text { to make a detailed plan. }\end{array}$ & 3 & $1-6$ & .81 & 3.32 & 1.20 \\
\hline & 3 & $\begin{array}{l}\text { I am confident that I can eat at least five } \\
\text { portions of fruit and vegetables every day. }\end{array}$ & 3 & $1-4$ & .79 & 3.09 & 0.72 \\
\hline & 4 & $\begin{array}{l}\text { I am confident that I can perform thirty } \\
\text { minutes or more of physical activities at } \\
\text { least three times per week. }\end{array}$ & 3 & $1-4$ & .68 & 2.83 & 0.63 \\
\hline \multirow[t]{4}{*}{ Planning } & 1 & $\begin{array}{l}\text { I have made a detailed plan about } \\
\text { when to floss my teeth. }\end{array}$ & 10 & $1-4$ & .93 & 2.06 & 0.84 \\
\hline & 2 & $\begin{array}{l}\text { I have had my own plan regarding } \\
\text { when to fasten the seat belt (i.e., at } \\
\text { which moment after getting into the car). }\end{array}$ & 3 & $1-6$ & .82 & 2.55 & 1.09 \\
\hline & 3 & $\begin{array}{l}\text { I have had made detailed plans about } \\
\text { which fruits and vegetables to eat. }\end{array}$ & 3 & $1-4$ & .79 & 2.80 & 0.72 \\
\hline & 4 & $\begin{array}{l}\text { I have made detailed plans about when to } \\
\text { perform physical activities. }\end{array}$ & 3 & $1-4$ & .83 & 3.43 & 0.67 \\
\hline \multirow[t]{2}{*}{ Recovery self-efficacy } & 1 & $\begin{array}{l}\text { If I have started to floss regularly, } \\
\text { I am confident that I can carry on, } \\
\text { even if I don't see immediate results. }\end{array}$ & 4 & $1-4$ & .94 & 2.71 & 0.93 \\
\hline & 2 & $\begin{array}{l}\text { I am confident that I am able to } \\
\text { resume regular use of seat belts, even } \\
\text { if I had failed to use them a couple of times. }\end{array}$ & 3 & $1-6$ & .67 & 4.01 & 1.11 \\
\hline
\end{tabular}


TABLE 1

Continued

\begin{tabular}{|c|c|c|c|c|c|c|c|}
\hline Construct & Sample & Item Example & $\begin{array}{l}\text { No. of } \\
\text { Items }\end{array}$ & $\begin{array}{l}\text { Response } \\
\text { Scale }\end{array}$ & $\alpha$ & $M$ & $S D$ \\
\hline & 3 & $\begin{array}{l}\text { I am confident that I am able to } \\
\text { resume eating at least five portions } \\
\text { of fruit and vegetables every day, } \\
\text { even if I have to get accustomed to it. }\end{array}$ & 3 & $1-4$ & .93 & 2.21 & 0.85 \\
\hline & 4 & $\begin{array}{l}\text { I am confident that I am able to } \\
\text { resume performing physical activity } \\
\text { regularly every day, even if I } \\
\text { don't see immediate results. }\end{array}$ & 3 & $1-4$ & .71 & 2.83 & 0.63 \\
\hline \multirow[t]{4}{*}{ Behavior } & 1 & $\begin{array}{l}\text { How often have you flossed } \\
\text { your teeth in the first of } \\
\text { the last four weeks? }\end{array}$ & 5 & $a$ & .81 & 4.64 & 4.81 \\
\hline & 2 & $\begin{array}{l}\text { Within the last six months, how often have } \\
\text { you used seat belts while traveling on the } \\
\text { rear seat/front passenger seat/in a taxi? }\end{array}$ & 3 & $1-5$ & .65 & 2.90 & 0.97 \\
\hline & 3 & $\begin{array}{l}\text { I eat at least five portions of fruit } \\
\text { and vegetables every day. }\end{array}$ & 3 & $1-4$ & .59 & 2.71 & 0.94 \\
\hline & 4 & $\begin{array}{l}\text { On how many days during the last } \\
\text { week and for how many minutes per session } \\
\text { did you perform fitness exercises to train } \\
\text { your muscle strength? }\end{array}$ & 2 & $a$ & $.33^{b}$ & $42.03^{c}$ & 22.63 \\
\hline
\end{tabular}

Note. Samples: 1 = flossing (students, German); 2 = seat belt use (students Polish); $3=$ dietary behavior (general sample, German); $4=$ physical activity (general sample, German). In Sample 2, the response scale was I (definitely not) to 6 (definitely true); 1 (never) to 5 (on all occasions). In Sample 3, the response scale was 1 (definitely not) to 4 (definitely true).

${ }^{a}$ Free response format. ${ }^{b}$ Pearson correlation (due to only two items). ${ }^{c}$ Minutes per week.

\section{Measures}

Intention, risk perception, outcome expectancies, and motivational self-efficacy were measured at Time 1. Measures of outcome expectancies, risk perception as well as both types of self-efficacy were based on results of an elicitation study. In the elicitation study, 100 students (ages
16-22) were asked open-ended questions about their beliefs about (a) pros and cons of using seat belts, (b) negative consequences that could occur if they would not use seat belts, (c) perceived barriers that would hinder an initiation of regular seat belt use, and (d) perceived barriers that would prevent them from resuming regular seat belt use

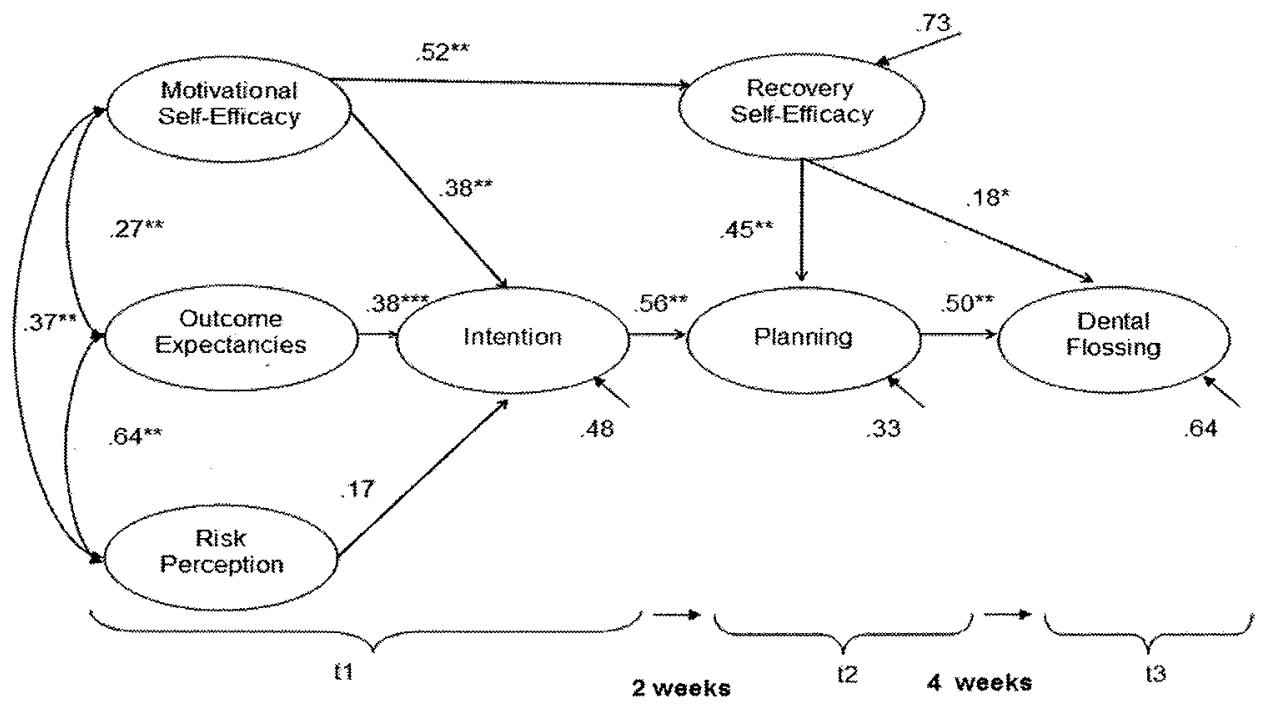

FIGURE 1 Structural equation model to predict dental flossing (Study I, $N=157$ ). 
TABLE 2

Correlations Between the Social-Cognitive Variables and Behavior Within the Four Samples

\begin{tabular}{|c|c|c|c|c|c|c|}
\hline Variable Sample & Outcome Expectancies & Motivational Self-Efficacy & Intention & Planning & Recovery Self-Efficacy & Behavior \\
\hline \multicolumn{7}{|l|}{ Risk perception } \\
\hline $1+x+2$ & $.61^{* *}$ & $.28^{* *}$ & $.47^{* *}$ & $.46^{* *}$ & $.22^{*}$ & $.30^{* *}$ \\
\hline 2 & .01 & .02 & .06 & .07 & .07 & .05 \\
\hline 3 & .01 & $-.09^{*}$ & -.01 & -.02 & -.03 & $-.13^{* *}$ \\
\hline 4 & $.13^{* *}$ & $-.21^{* *}$ & -.02 & $-.13^{*}$ & $-.29^{* *}$ & -.09 \\
\hline \multicolumn{7}{|c|}{ Outcome expectancies } \\
\hline 1 & & .17 & $.53^{* *}$ & $.31^{* *}$ & $.20^{*}$ & $.33^{* *}$ \\
\hline 2 & & $.29^{* *}$ & $.50^{* *}$ & $.28^{* *}$ & $.26^{* *}$ & $.36^{* *}$ \\
\hline 3 & & $.43^{* *}$ & $.32^{* *}$ & $.25^{* *}$ & $.33^{* *}$ & $.25^{* *}$ \\
\hline 4 & & $.35^{* *}$ & $.36^{* *}$ & $.15^{* *}$ & $.21^{* *}$ & .02 \\
\hline \multicolumn{7}{|c|}{ Motivational self-efficacy } \\
\hline 1 & & & $.40^{* *}$ & $.46^{* *}$ & $.34^{* *}$ & $.38^{* *}$ \\
\hline 2 & & & $.35^{* *}$ & $.27^{* *}$ & $.13^{*}$ & $.10^{*}$ \\
\hline 3 & & & $.52^{* *}$ & $.40^{* *}$ & $.51^{* *}$ & $.45^{* *}$ \\
\hline 4 & & & $.56^{* *}$ & $.32^{* *}$ & $.13^{*}$ & $.41^{* *}$ \\
\hline \multicolumn{7}{|l|}{ Intention } \\
\hline 1 & & & & $.60^{* *}$ & $.44^{* *}$ & $.45^{* *}$ \\
\hline 2 & & & & $.35^{* *}$ & $.28^{* *}$ & $.31^{* *}$ \\
\hline 3 & & & & $.50^{* *}$ & $.47^{* *}$ & $.36^{* *}$ \\
\hline 4 & & & & $.30^{* *}$ & $.34^{* *}$ & $.15^{*}$ \\
\hline \multicolumn{7}{|l|}{ Planning } \\
\hline 1 & & & & & $.44^{* *}$ & $.50^{* *}$ \\
\hline 2 & & & & & $.31^{* *}$ & $.36^{* *}$ \\
\hline 3 & & & & & $.43^{* *}$ & $.49^{* *}$ \\
\hline 4 & & & & & $.47^{* *}$ & $.22^{* *}$ \\
\hline \multicolumn{7}{|c|}{ Recovery self-efficacy } \\
\hline 1 & & & & & & $.34^{* *}$ \\
\hline 2 & & & & & & $.41^{* *}$ \\
\hline 3 & & & & & & $.45^{* *}$ \\
\hline 4 & & & & & & $.19^{* *}$ \\
\hline
\end{tabular}

Note. Samples: 1 = flossing (students, German); $2=$ seat belt use (students, Polish); $3=$ nutrition behavior (general sample, German); $4=$ physical activity (general population sample, German).

${ }^{*} p<.05 .{ }^{* *} p<.01$.

after failing to do so. The most frequent responses were used to form the items of respective measures. Items used to measure planning were adopted from a previous study on self-protective behavior (4). Planning and recovery self-efficacy were measured at Time 2 ( 1 month later). Seat belt use was measured at Time 3 (6 months later). Compared to objective measures, self-reports have been found to produce similar rates of seat belt use (22). Item examples as well as scale statistics can be found in Table 1.

\section{Results}

The hypothesized model fit the data well, with, RMSEA $=.05(90 \% \mathrm{CI}=.04, .05), \chi^{2} / d f=2.04, \mathrm{CFI}=.99$, $\mathrm{TLI}=.98, \chi^{2}(179)=363, p<.001$. Figure 2 displays the parameter estimates (standardized solution). Planning and self-efficacy emerged as mediators, as hypothesized. Motivational self-efficacy accounted for $8 \%$ of variance of the recovery self-efficacy, attesting to the discriminant validity of the two constructs. Of the planning variance,
$22 \%$ has been accounted for by intention and volitional self-efficacy, and $42 \%$ of the seat belt use variance has been explained jointly by planning and recovery self-efficacy. The indirect effect of intention on seat belt use was .18 $(p<.05)$.

\section{STUDY III: DIETARY BEHAVIOR}

The third study examines dietary behavior in a sample of 700 internet users in Germany. The following analysis applies the HAPA model to a longitudinal data set with two points in time covering a 4-week period. The questions are whether the model fit the data and whether self-efficacy and planning constitute mediators.

\section{Method}

\section{Participants}

An online study was conducted using the software dynQuest (23). Nineteen hundred and five potential study participants responded to the initial Web page. Of these, 1,659 


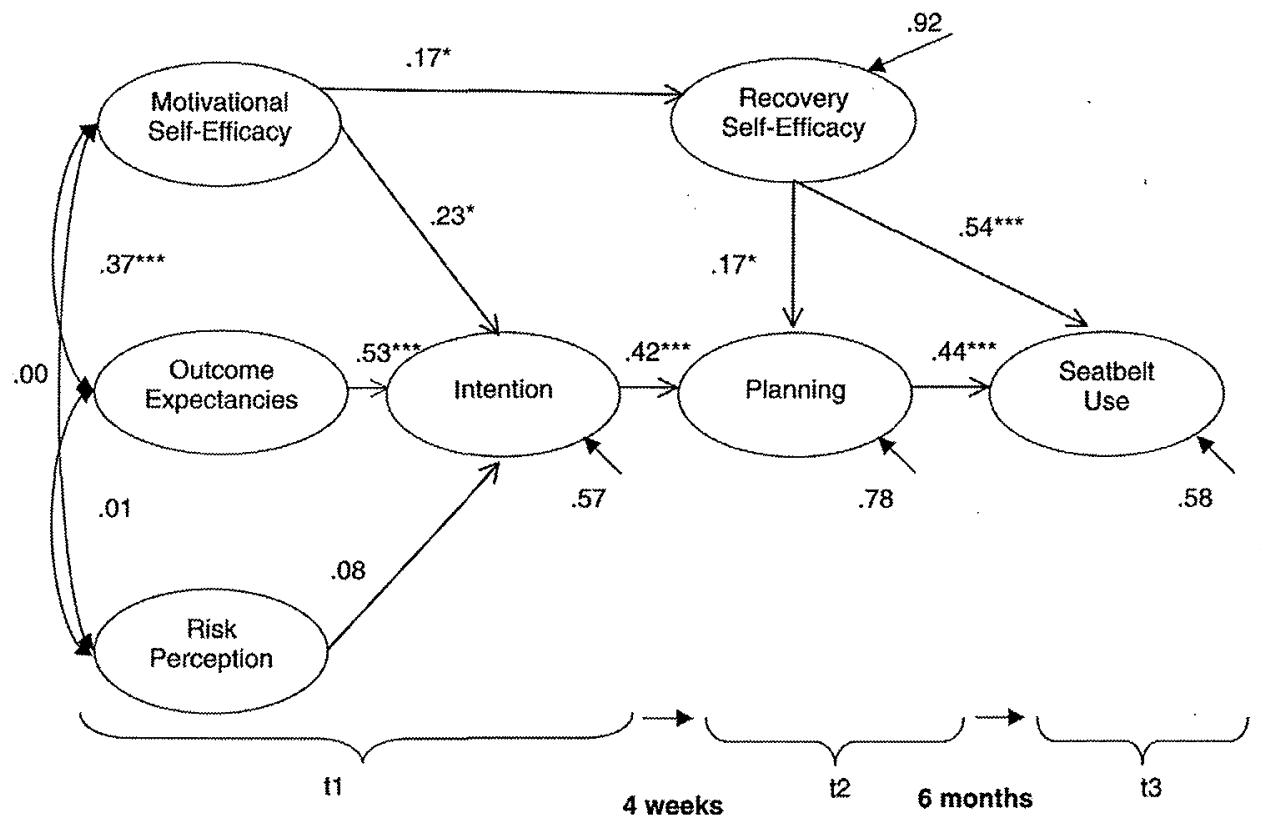

FIGURE 2 Structural equation model to predict seat belt use (Study II, $N=298$ ).

individuals $(87.1 \%)$ provided their e-mail addresses to receive an invitation for a follow-up assessment. Seven hundred respondents $(42.2 \%$ of those who could potentially participate) answered the follow-up questionnaire. Dropout analyses in terms of sex, age, and baseline behavior showed no significant differences between the initial sample and those who completed both measurement points in time, indicating that the longitudinal sample was representative for the initial one. Thus, the final sample consisted of 700 participants, aged 16 to 78 years $(M=37.68, S D=12.31) ; 72.8 \%$ of them were women. About $50 \%$ of the respondents were living with a partner; $72.7 \%$ had completed high school, and $50 \%$ had a university degree.

\section{Procedure}

Participants were recruited by means of personal invitation (17.4\%), a press release (radio, newspaper and magazine reports; $27.1 \%$ ), and advertisements posted on a university Web site with a link to the questionnaire $(32.7 \%)$. After the study was introduced, participants provided informed consent and followed a link to a selfadministered questionnaire. After 4 weeks, all participants who had provided their e-mail addresses were approached via e-mail to answer a follow-up questionnaire (Time 2).

\section{Measures}

The Time 1 questionnaire assessed risk perception, motivational self-efficacy, outcome expectancies, and behavioral intentions. At Time 2, planning, recovery self-efficacy and behavior (eating at least five portions of fruits and vegetables every day) were measured. All social-cognitive variables were assessed using 4-point scales, ranging from 1 (totally disagree) to 4 (totally agree). Item examples as well as scale statistics can be found in Table 1 .

\section{Results}

The hypothesized model fit the data well with RMSEA $=.05(90 \% \mathrm{CI}=.05, .06), \chi^{2} / d f=2.84, \mathrm{CFI}=.95$, $\mathrm{TLI}=.93, \chi^{2}(176)=500, p<.001$. Figure 3 displays the parameter estimates (standardized solution). All manifest variables loaded significantly $(p<.05)$ on their hypothesized factors. Figure 3 displays the parameter estimates (standardized solution). Planning and self-efficacy emerged as mediators, as hypothesized. Motivational self-efficacy accounted for $38 \%$ of the variance of recovery self-efficacy. Of the planning variance, $53 \%$ has been accounted for by intention and recovery self-efficacy, and $73 \%$ of the dietary behavior variance has been explained jointly by planning and recovery self-efficacy. The indirect effect of intention on dietary behavior was $.40(p<.05)$.

\section{STUDY IV: PHYSICAL ACTIVITY}

The fourth study examines physical activity in a sample of 365 internet users in Germany. The following analysis applies the HAPA model to a longitudinal data set with two points in time covering a 5 -week period. The question 


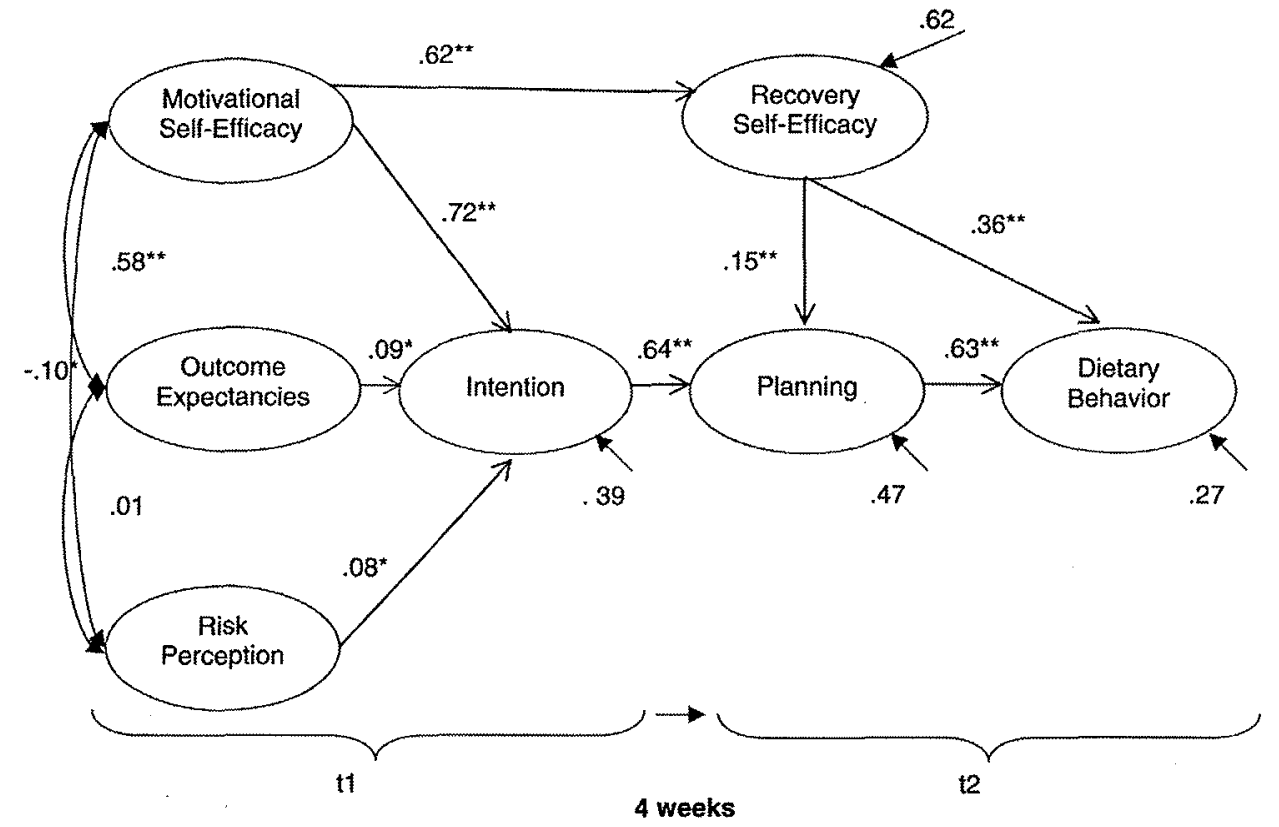

FIGURE 3 Structural equation model to predict dietary behavior (Study III, $N=700$ ).

is whether the model fit the data and whether self-efficacy and planning constitute mediators.

\section{Method}

\section{Participants}

An online study was conducted using the software dynQuest (23). Twelve hundred and seventy-nine potential study participants visited the start page of the Web site. Of these, 881 persons $(68.9 \%)$ provided their e-mail addresses to receive an invitation for a follow-up assessment. Three hundred sixty-five respondents $(41.4 \%$ of those who could potentially participate) answered the follow-up questionnaire. Dropout analyses in terms of sex, age, and baseline behavior showed no significant differences between the initial sample and those who completed both measurement points in time, indicating that the longitudinal sample was representative for the initial sample. Thus, the final sample consisted of 365 participants, ages 16 to $64(M=37.01$, $S D=9.99) ; 81.4 \%$ were women. About $57.5 \%$ of respondents were living with a partner, $72.2 \%$ had completed high school, and $44.4 \%$ held a university degree.

\section{Procedure}

Respondents were recruited by means of personal invitations sent via e-mail and advertisements placed on a university Web site with a link to the questionnaire. After the study was introduced, participants provided informed consent and followed a link to a self-administered questionnaire. After 5 weeks, all participants who provided their e-mail address were approached via e-mail to answer a follow-up questionnaire (Time 2).

\section{Measures}

The Time 1 questionnaire assessed risk perception, motivational self-efficacy, outcome expectancies, and behavioral intentions. At Time 2, planning, recovery selfefficacy, and behavior (days and minutes performance of fitness activities and exercises to train muscle strength) were measured. All psychological variables were assessed using 4-point scales from 1 (totally disagree) to 4 (totally agree). Item examples as well as scale statistics can be found in Table 1.

\section{Results}

The hypothesized model fit the data well, with RMSEA $=.06(90 \% \mathrm{CI}=.05, .06), \chi^{2} / d f=2.15, \mathrm{CFI}=.92$, $\mathrm{TLI}=.89, \chi^{2}(161)=346, p<.001$. Figure 4 displays the parameter estimates (standardized solution). All manifest variables loaded significantly $(p<.05)$ on their hypothesized factors. Figure 4 displays the parameter estimates (standardized solution). Planning and self-efficacy emerged as mediators. Forty-three percent of the variance of the recovery self-efficacy has been accounted for by motivational self-efficacy. Of the planning variance, $30 \%$ has been accounted for by intention and recovery self-efficacy, and $21 \%$ of the physical activity variance has been explained jointly by planning and recovery self-efficacy. The indirect effect of intention on physical activity was $.04(p>.05)$. 


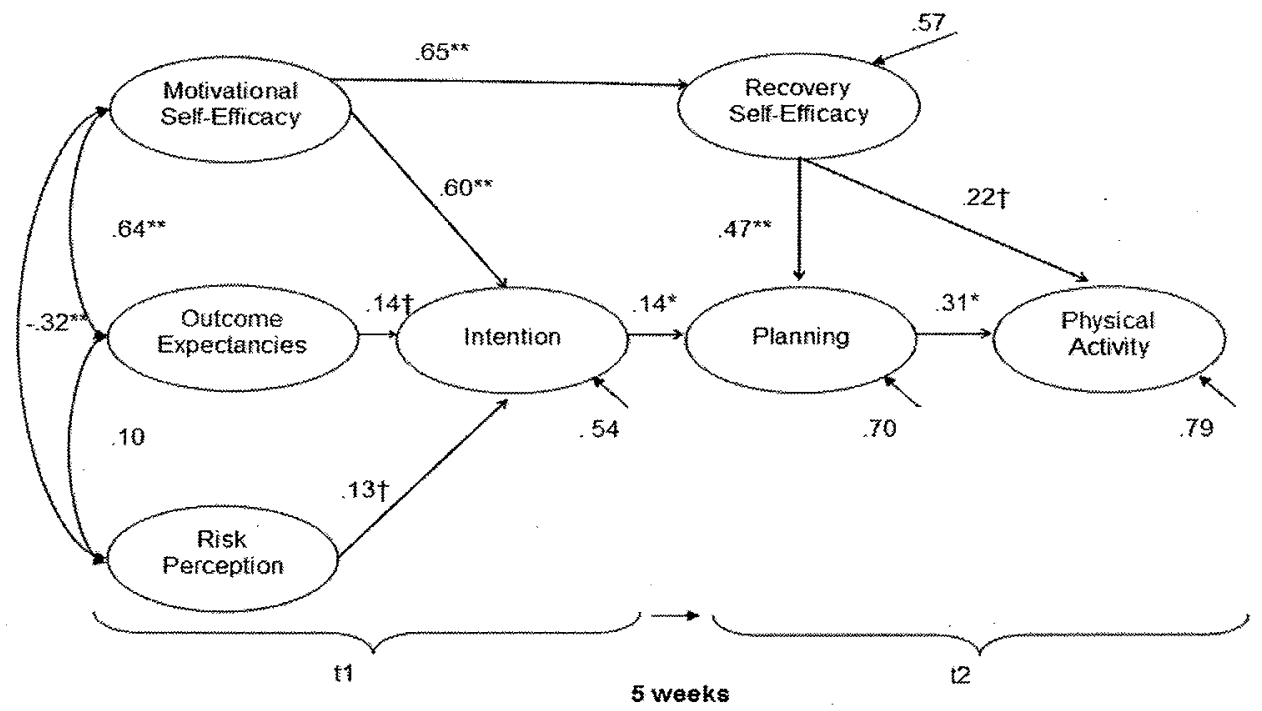

FIGURE 4 Structural equation model to predict physical activity (Study IV, $N=365$ ). Note. ${ }^{\dagger} \mathrm{p}<.10 .{ }^{*} \mathrm{p}<.05 .{ }^{* *} \mathrm{p}<.001$.

\section{GENERAL DISCUSSION}

Four longitudinal studies on health behaviors presented here were based on different samples from different countries. In all studies, the HAPA model fit the data well, suggesting that the selected set of variables and the specified relationships may be appropriate to describe such data. These findings also replicate the results of Luszczynska and Schwarzer (4) on breast self-examination.

Strategic planning and recovery self-efficacy were specified as proximal predictors of behavior, and planning was supposed to bridge the gap between intentions and behavior. Results indicate that these constructs indeed serve their purpose. This is in line with previous research, suggesting that self-reported planning mediates between intention and behavior $(24,25)$. Findings of the studies differ, however, in some respects. Different amounts of behavioral variance were accounted for by the two predictors planning and self-efficacy ( $36 \%$ for dental flossing, $42 \%$ for seat belt use, $73 \%$ for dietary behavior, and $21 \%$ for physical activity). It might be that some behaviors are less intentional and rather prescribed by routine, external circumstances, and social support. These variables do not tap these potential factors of influence. Moreover, it might be that some behaviors require a one-time decision (e.g., to use seat belts) as opposed to others that need to be regulated on a daily or weekly basis (e.g., physical activity).

Different amounts of the planning variance were accounted for by the two predictors intentions and recovery self-efficacy $(67 \%$ for dental flossing, $22 \%$ for seat belt use, $53 \%$ for dietary behavior, and $30 \%$ for physical activity). Theoretically, action planning constitutes an elaboration of the intention, and, therefore, a close empirical relationship between the two constructs was expected, even with a temporal distance. In the online study on physical activity, however, planning was almost unrelated to the intention, and there was also no indirect effect of intention on behavior. In other studies using the same instruments, the HAPA variables were highly predictive of physical exercise (5-7). One has to distinguish between medically recommended exercise regimens and daily physical activity. The former seems to be guided by intentions and plans, whereas the latter might be based on routine, external circumstances, and social support.

The fact that risk perception was not significantly related to any of the variables under study, as opposed to the other social-cognitive variables, raises general questions about how health behaviors can be modified. Risk perceptions may be less important in preventive health behaviors such as the ones studied here than in detection behaviors such as breast self-examination or cancer screenings. The fear appeal approach has focused on using risk communication to let people recognize how much they are at risk for illness or injury. The usefulness of such interventions as stand-alone-strategies is doubtful at the least (26). These findings would emphasize a different strategy by making people aware of their resources, that is, their skills and strategies (e.g., planning) to change a refractory behavior.

These findings contribute to our understanding of some mechanisms that are involved in health behavior change. The traditional view, namely that intentions are the best predictors of behavior (27), has become increasingly questionable in the face of findings such as in these four studies. Planning and recovery self-efficacy appear to be the best direct predictors of various health behaviors. This is theoretically meaningful since intenders face unforeseen barriers and are challenged by temptations. One's confidence in being able to meet such demands motivates individuals to invest more effort and to persist longer when 
it comes to translating intentions into action. Maintenance of a behavior is facilitated by one's confidence in being able to recover from setbacks.

Some limitations need to be addressed. The current fitted models need not necessarily represent the only true models; there may be others that also fit the data. Prediction of behavior can be further improved by other variables, having a direct impact on behavior (7). These analyses are based on longitudinal data, but we did not analyze behavioral change. In all domains of human functioning, baseline behaviors are typically the best predictors of later behaviors, which imply that their inclusion in the analysis would mask the effects of social-cognitive variables (28). Baseline behaviors are themselves a product of previous social-cognitions as research using cross-lagged panel designs to test reciprocal effects of recovery self-efficacy, intention, and behavior provide support for the assumption that, indeed, these cognitions affect behavior $(29,30)$. However, it might be possible that not controlling for initial behavior in this study could produce an overestimation of any potential effect of the predictors.

Another limitation refers to the measurement of health behaviors and social cognitions. The criterion variable is self-reported, and there is no direct possibility to examine the validity of these self-reports. However, there is evidence for the validity of self-reports, for example in the case of physical activity (31), healthy nutrition (32), and seat belt use (33). The measures of social cognitions were based on respective measures used in previous research $(4,5,6,13,34)$, however no extensive study on psychometric properties of these measures were conducted. Reliability coefficients for some measures of social cognitions were low. The results have to be treated with caution and firm causal interpretations cannot be made from these data.

In spite of these limitations, these four studies are constructive because of their consistency across behaviors and samples, research contexts, and time spans. Also, they replicate an earlier finding on breast self-examination (4). Individuals who intend to change their health behaviors might benefit from treatments that improve recovery selfefficacy and planning. Some promising attempts to design such interventions have been made $(6,34)$. Intervention designs would also benefit from evidence on the stage matching of treatments that has been gained in the context of the Transtheoretical Model $(35,36)$.

\section{REFERENCES}

(1) Maddux JE, Rogers RW: Protection motivation and selfefficacy: A revised theory of fear appeals and attitude change. Journal of Experimental Social Psychology. 1983, 19:469-479.

(2) Ajzen I: Perceived behavioral control, self-efficacy, locus of control, and the theory of planned behavior. Journal of Applied Social Psycholog. 2002, 32:665-683.
(3) Sheeran P: Intention-behavior relations: A conceptual and empirical review. In Stroebe W, Hewstone $M$ (eds), European Review of Social Psychology (Vol. 12). Chichester, England: Wiley, 2002, 1-30.

(4) Luszczynska A, Schwarzer R: Planning and self-efficacy in the adoption and maintenance of breast self-examination: A longitudinal study on self-regulatory cognitions. Psychology and Health. 2003, 18:93-108.

(5) Scholz U, Sniehotta FF, Schwarzer R: Predicting physical exercise in cardiac rehabilitation: The role of phase-specific self-efficacy beliefs. Journal of Sport \& Exercise Psychology. 2005, 27:135-151.

(6) Lippke S, Ziegelmann JP, Schwarzer R: Initiation and maintenance of physical exercise: Stage-specific effects of a planning intervention. Research in Sports Medicine. 2004, 12:221-240.

(7) Sniehotta FF, Scholz U, Schwarzer R: Bridging the intention-behaviour gap: Planning, self-efficacy, and action control in the adoption and maintenance of physical exercise. Psychology \& Health. 2005, 20:143-160.

(8) Ziegelmann JP, Lippke S, Schwarzer R: Adoption and maintenance of physical activity: Planning interventions in young, middle-aged, and older adults. Psychology \& Health. 2006, 21:145-163.

(9) Marlatt GA, Baer JS, Quigley LA: Self-efficacy and addictive behavior. In Bandura A (ed), Self-Efficacy in Changing Societies. New York: Cambridge University Press, 1995, 289-315.

(10) Luszczynska A, Sutton S: Maintenance and recovery self-efficacy beliefs predict maintenance of rehabilitation exercises or recovery from relapse among patients after MI. Rehabilitation Psychology 2006, 51:314-321.

(11) Rodgers WM, Hall CR, Blanchard CM, McAuley E, Munroe $\mathrm{KJ}$ : Task and scheduling self-efficacy as predictors of exercise behaviour. Psychology and Health. 2002, 27:405-416

(12) Rodgers W, Sullivan MJL: Task, coping and scheduling self-efficacy in relation to frequency of physical activity. Journal of Applied Social Psychology. 2001, 31:741-753.

(13) Schwarzer R, Renner B: Social-cognitive predictors of health behavior: Action self-efficacy and coping selfefficacy. Health Psychology. 2000, 19:487-495.

(14) Lewin K: Group decision and social change. In Newcomb TM, Hartley EL (eds), Readings in Social Psychology. New York: Holt, 1947, 330-344.

(15) Leventhal $\mathrm{H}$, Singer $\mathrm{R}$, Jones $\mathrm{S}$ : Effects of fear and specificity of recommendation upon attitudes and behavior. Journal of Personality and Social Psychology. 1965, 2:20-29.

(16) Gollwitzer PM: Implementation intentions: Strong effects of simple plans. American Psychologist. 1999, 54:493-503.

(17) Armitage CJ: Evidence that implementation intentions reduce dietary fat intake: A randomized trial. Health Psychology. 2004, 23:319-323.

(18) Arbuckle JL, Wothke W: Amos 4.0 User Guide. Chicago: Small Waters, 1999.

(19) Hu L, Bentler PM: Evaluating model fit. In Hoyle RH (ed), Structural Equation Modeling. Concepts, Issues, and Applications. Thousand Oaks, CA: Sage, 1995, 76-99.

(20) Rise J, Åstrøm AN, Sutton S: Predicting intentions and use of dental floss among adolescents: An application of the theory of planned behavior. Psychology and Health. 1998, 13:223-236. 
(21) Schüz B, Sniehotta FF, Wiedemann, A, Seemann R: Adherence to a daily flossing regimen in university students: Effects of planning when, where, how, and what to do in the face of barriers. Journal of Clinical Periodontology 2006, 33:612-619.

(22) McKnight RH, Dawson SK: Seat belt use in Kentucky-a comparison of five measures. The Journal of the Kentucky Medical Association. 1996, 94:110-114.

(23) Rademacher JDM, Lippke S: Dynamic online surveys and experiments with the free open source software dynQuest. Behavior Research Methods (in press).

(24) Jones F, Abraham C, Harris P, Schulz J, Chrispin C: From knowledge to action regulation: Modeling the cognitive prerequisites of sun screen use in Australian and UK samples. Psychology and Health. 2001, 16:191-206.

(25) Norman P, Conner M: The Theory of Planned Behavior and exercise: Evidence for the mediating and moderating roles of planning on intention-behavior relationships. Journal of Sport and Exercise Psychology. 2005, 27: 488-504.

(26) Calisir F, Lehto MR: Young drivers' decision making and safety belt use. Accident Analysis \& Prevention. 2002, 34:793-805.

(27) Fishbein M, Ajzen I: Belief, Attitude, Intention, and Behavior: An Introduction to Theory and Research. Reading, MA: Addison-Wesley, 1975.

(28) Bandura A: Self-Efficacy: The Exercise of Control. New York: Freeman, 1997.
(29) Luszczynska A, Mazurkiewicz M, Ziegelmann JP, Schwarzer R: Recovery self-efficacy and intention as predictors of running: A cross-lagged panel analysis over a two-year period. Psychology of Sport and Exercise 2007, 8:247-260.

(30) Weinstein ND: Misleading tests of health behavior theories. Annals of Behavioral Medicine (in press, 2006).

(31) Miller DJ, Freedson PS, Kline GM: Comparison of activity levels using the Caltrac accelerometer and five questionnaires. Medicine and Science in Sports and Exercise. 1994, 26:376-382.

(32) Armitage CJ, Conner M: The theory of planned behavior: Assessment of predictive validity and 'perceived control'. British Journal of Social Psychology. 1999, 38:35-54.

(33) Nelson DE: Validity of self-reported data on injury prevention behavior: Lessons from observational and self-reported surveys of safety belt use in the US. Injury Prevention. 1996, 2:67-69.

(34) Luszczynska A, Sobczyk A, Abraham C: Planning to lose weight: RCT of an implementation intention prompt to enhance weight reduction among overweight and obese women. Health Psychology (in press).

(35) DiClemente, CC, Prochaska JO: Self-change and therapy change of smoking behavior: A comparison of processes of change in cessation and maintenance. Addictive Behaviors. 1982. 7:133-142.

(36) Prochaska JO, Velicer WF, Rossi JS, et al.: Stages of change and decisional balance for 12 problem behaviors. Health Psychology. 1994, 13:39-46. 